\title{
Occult Hepatitis C Virus Infection in Patients with Diabetic Nephropathy: Epidemiological and Clinical Implications
}

\author{
Teresa Olea, Inmaculada Castillo, Elena González, Lucía Rodríguez-Gayo, Javier Bartolomé, \\ Marco Vaca, Juan Antonio Quiroga, Rosario Madero,Rafael Selgas, Vicente Carreño
}

\begin{abstract}
Background:A high prevalence of hepatitis C virus (HCV) infection in patients with diabetic kidney disease (DKD) has been reported. However, the epidemiology and relationship between DKD and occult HCV infection (OCI)are unknown.Objetives: To determine the prevalence of OCI in a population without conventional markers of $\mathrm{HCV}$ infection diagnosed with DKD, and to study its possible clinical implications.Study design: This prospective study included 125 anti-HCV and serum HCV-RNA-negative patients with DKD for the presence of OCI. HCV-RNA was tested by real-time reverse transcription PCR in peripheral blood mononuclear cells and in plasma after ultracentrifugation. Results: OCI was positive in 10 patients $(8 \%)$. The patients with OCI had significantly higher ferritin levels $(p=.002)$ and monoclonal gammopathy $(30 \%[3 / 10]$ vs. $0.87 \%[1 / 115]$ than the patients without OCI $[p=.003])$. We found similar plasma ALT and GGT levels and $\mathrm{HbA1C}$ in both groups. At the end of the follow-up, the progression rate of renal disease tended to be faster in the group with OCI relative to the negative one, but without a significant difference. We did not find an association between OCI and cardiovascular morbidity. Conclusions: There was an $8 \%$ prevalence of OCI in patients with chronic renal failure secondary to DKD, higher than in the general population. This occult infection does not appear to play a role in the control of diabetes, cardiovascular risk or steatosis. However, the progression rate of renal disease tended to be faster, and the incidence of associated monoclonal gammopathy was significant.
\end{abstract}

Index Terms - Diabetes Kidney Disease, Type 2 diabetes mellitus, Occult hepatitis $\mathrm{C}$ virus.

\section{INTRODUCTION}

Type 2 diabetes mellitus (T2DM) and hepatitis $\mathrm{C}$ virus

Teresa Olea, Nephrology Deparment, Hospital Universitario La Paz. REDinREN. Madrid, Spain.

Inmaculada Castillo,Foundation for the Study of Viral Hepatitis, Madrid, Spain

Elena González. Nephrology Deparment, Hospital Universitario La Paz. REDinREN. Madrid, Spain.

Lucía Rodríguez- Gayo. Nephrology Deparment, Hospital Universitario La Paz.

Javier Bartolomé. Foundation for the Study of Viral Hepatitis, Madrid, Spain.

Marco Vaca. Nephrology Deparment, Hospital Universitario La Paz. Juan Antonio Quiroga. Foundation for the Study of Viral Hepatitis, Madrid, Spain.

Rosario Madero. Department of Biostatistics. Hospital Universitario La Paz. Madrid, Spain.

Rafael Selgas. Nephrology Deparment, Hospital Universitario La Paz. Professor at Universidad Autónoma de Madrid. REDinREN. Madrid, Spain. Vicente Carreño. Foundation for the Study of Viral Hepatitis, Madrid, Spain.
(HCV) are two major public health problems worldwide. Previous reports have shown a high prevalence of $\mathrm{HCV}$ infection in patients with diabetic kidney disease (DKD) $[1,2]$. The association between these two diseases is a matter of debate [3].On one hand, this association is supported by two meta-analyses [4,5],longitudinal studies, and by described pathophysiological mechanisms by which HCV infection causes insulin resistance [6-10]. Both entities share metabolic complications such as resistance to insulin, fatty liver, subclinical inflammation and perhaps cardiovascular disease, resulting in a significant increase in morbidity and premature mortality [3]. On the other hand, a recent cohort study of 15,128 American patients (NHANES) has challenged this dogma because it found that the prevalence of diabetes or prediabetes was not associated with $\mathrm{HCV}$ infection status[11].

Occult HCV infection (OCI) is characterized by the presence of HCV-RNA in the liver or in peripheral blood mononuclear cells in the absence of serological markers [12]. Complementary studies have demonstrated that OCI can also be diagnosed by concentrating $2 \mathrm{ml}$ of serum by ultracentrifugation, followed by $\mathrm{HCV}-\mathrm{RNA}$ detection by real-time PCR [13]. OCI, as a state of nonapparent but real $\mathrm{HCV}$ infection, could explain these differences between $\mathrm{HCV}$ infection and T2DM. Furthermore, our group has demonstrated an association between OCI and a large spectrum of immune-mediated glomerular diseases, including a role in the progression of the disease [14].

\section{OBJETIVES}

We have aimed to better understand the epidemiological and clinical implications of OCI in a population of T2DM and DKD. We also reviewed the progression of DKD according to OCI status, and its association with steatosis, diabetes control and cardiovascular complications.

\section{A. Study design}

This prospective study included 125 adult patients visiting the nephrology departmentdue to DKDbetween 2012 and 2013. Diabetes was defined using the standard American Diabetes Association criteria, and was confirmed by laboratory testing. DKD was characterized as long-term diabetes with albuminuria (ratio of albumin to creatinine $>30$ $\mathrm{mg} / \mathrm{g}$ ), impaired renal function (estimated glomerular filtration rate [eGFR] $<60 \mathrm{ml} /$ minute per $1.73 \mathrm{~m} 2$ ), or both. Other nephropathies were ruled out by an expert 
nephrologist. All the included patients tested negative for anti-HCV, hepatitis B surface antigenand anti-HIV using a routine commercial test (INVITROS Anti-HCV Assay, Ortho Clinical Diagnostics, Raritan, NJ; Enzygnost hepatitis B surface antigen 5.0and Enzygnost Anti-HIV 1/2 Plus Siemens Healthcare Diagnostics, Marburg, Germany).

The study was approved by the Research Ethics Committee of University Hospital La Paz and was conducted according to the Declaration of Helsinki. Each patient provided written informed consent and was then tested for occult $\mathrm{HCV}$ infection. An average follow-up of $17.5 \pm 9$ months was used to explore outcomes of kidney function and incidence of cardiovascular complications. Demographic, epidemiological, clinical and laboratory parameters of the 125 patients with DKD at OCI testing are shown in Table 1.

Hematuria was defined as a red blood cell count greater than 5 per high-power field in urinary sediment. Waist circumference $\leq 102 \mathrm{~cm}$ for men and $\leq 88 \mathrm{~cm}$ for women were considered normal. Previous blood transfusions, surgical procedures, household contacts and partners diagnosed with $\mathrm{HCV}$ infection, as well as the presence of a tattoo or piercing were recorded as potential risk factors for $\mathrm{HCV}$ infection Table I: Demographic and clinical characteristics of the patients at inclusion.

$\begin{array}{ll}\text { Age }(\text { years; mean } \pm \text { SD) } & 73.7 \pm 10.04 \\ \text { Male (n; \%) } & 115 ; 92 \\ \text { Type of diabetes: }(\mathrm{n} ; \%) & \\ \text { I } & 10 ; 8 \\ \text { II } & 115 ; 92 \\ \text { Risk Factors for HCV infection: }(\mathrm{n} ; \%) & \\ \text { Previous blood transfusion } & 35 ; 28 \\ \text { Tattoo/drug addiction } & 2 ; 1.6 \\ \text { Household HCV contact } & 2 ; 1.6 \\ & \\ \text { HBV infection (n; \%) } & 9 ; 15 \\ \text { ALT (IU/L; mean } \pm \text { SD) } & 24.3 \pm 23.4 \\ \text { AST (IU/L; mean } \pm \text { SD) } & 43.2 \pm 22 \\ \text { GGT (IU/L; mean } \pm \text { SD) } & 47.8 \pm 66.7 \\ \text { Creatinine (mg/dl) } & 1.91 \pm 0.83 \\ \text { Creatinine clearance (ml/min per } 1,73 \text { m² }^{2} & 44.2 \pm 26.8 \\ \text { Proteinuria (g/24h) } & 1.24 \pm 1.86\end{array}$

\section{HBV: hepatitis B virus; ALT: alanine transaminase; AST:}

aspartate transaminase; GGT: gamma-glutamyl transferase

\section{B. HCV-RNA detection}

Plasma and peripheral blood mononuclear cells (PBMCs) were isolated from anticoagulated blood samples collected from all patients at the time of inclusion in the study. The plasma samples were stored at $-80^{\circ} \mathrm{C}$ and the PBMCs at $-20^{\circ} \mathrm{C}$ in RNAlater solution (Ambion, Austin, TX) until detection of HCV-RNA.

Two milliliters of plasma were ultracentrifuged over a $10 \%$ sucrose cushion for $17 \mathrm{~h}$ at $100,000 \times \mathrm{g}$ and $4^{\circ} \mathrm{C}$ to concentrate HCV particles [13]. The pellet was dissolved in TE buffer (Tris-HCl 10 mM, EDTA 10 mM; pH 7.5). Total RNA was isolated with the Trizol LS Reagent (Invitrogen, Carlsbad, CA), then precipitated, and the RNA pellet was dissolved in diethyl-pyrocarbonate-treated water. Total RNA from the PBMCs was isolated with SV Total RNA Isolation System (Promega, Madison, WI). After precipitation, the pellets were dissolved in diethyl-pyrocarbonate-treated water, and the RNA concentration was determined by spectrophotometry.

Detection of HCV-RNA was performed using $5 \mu \mathrm{l}$ of total RNA isolated from $2 \mathrm{ml}$ of ultracentrifuged plasma or using $0.5 \mu \mathrm{g}$ of total RNA from PBMCs by real-time reverse transcription polymerase chain reaction (RT-PCR) with the Tth enzyme for cDNA synthesis as described [13]. Real-time PCR was performed with FRET probes in a LightCycler (Roche Diagnostics, Mannheim, Germany) with $2 \mu$ of cDNA in a final volume of $20 \mu \mathrm{l}$, using the LightCycler FastStart DNA Master HybProbe Kit (Roche Diagnostics), as reported [13]. For HCV-RNA quantification, a standard curve constructed with 10-fold dilutions of a synthetic HCV-RNA was used. The sensitivity of this assay was of three HCV-RNA copies per reaction [13].

Negative controls (repeated HCV-RNA-negative plasma and PBMC samples from four healthy volunteers) and reagent blanks, in which total RNA was replaced with PCR-grade water, were included in each PCR run. All these negative controls were coprepared with the samples and accompanied the samples through the entire RT-PCR process.

\section{Statistical analysis}

The categorical variables were compared using the chi-squared test or Fisher's exact test, as appropriate. The continuous variables were compared using Student's t-test or the Mann-Whitney U-test.

\section{RESULTS}

Of the 125 studied patients, 7tested positive for the presence of HCV-RNA in PBMCs, with a median concentration of $1980 \mathrm{HCV}-\mathrm{RNA}$ copies per $\mu \mathrm{g}$ total RNA (range 110-4820). In addition, HCV-RNA was detected in plasma after ultracentrifugation of $2 \mathrm{ml}$ of plasma in another three patients at concentrations of 120, 135 and 140 HCV-RNA copies per $\mathrm{ml}$ plasma. No patient was simultaneously positive for HCV-RNA in PBMCs and in plasma after ultracentrifugation. Thus, we found a prevalence of OCI in our series of 10/125 (8\%); these patients had detectable viral RNA in PBMCs or in plasma after ultracentrifugation despite the absence of anti-HCV antibodies.

Table 2 displays the demographic characteristics, clinical features and cardiovascular risk factors of the two groups of patients with DKD according to the presence or not of OCI. Most of the variables were similar. 
Table II: Demographic, clinical and analytical data according to occult negative/positive HCV infection.

\begin{tabular}{|c|c|c|}
\hline & $\begin{array}{l}\text { Occult negative HCV } \\
\text { infection }(\mathrm{n}=115)\end{array}$ & $\begin{array}{l}\text { Occult positive HCV } \\
\text { infection }(n=10)\end{array}$ \\
\hline Age (years; mean \pm SD) & $73.7 \pm 10$ & $74.9 \pm 8.6$ \\
\hline Male $(\mathrm{n} ; \%)$ & $78 ; 70.9$ & $60 ; 61.3$ \\
\hline Risk factors for acquisition of $\mathrm{HCV}(\%)$ & 1.4 & 1.1 \\
\hline Smoking $(\mathrm{n} ; \%)$ & $7 ; 11.8$ & $2 ; 9.5$ \\
\hline Systolic blood pressure (mmHg) & $134.6 \pm 12.1$ & $135.5 \pm 22.6$ \\
\hline Diastolic blood pressure $(\mathrm{mmHg})$ & $64.0 \pm 17.9$ & $66.8 \pm 10.9$ \\
\hline $\operatorname{BMI}\left(\mathrm{kg} / \mathrm{m}^{2}\right)$ & $31.7 \pm 6.5$ & $30.8 \pm 6$ \\
\hline Waist circumference $(\mathrm{cm})$ & $114.5 \pm 13.3$ & $107.1 \pm 14$ \\
\hline Cholesterol(mg/dl) & $140.4 \pm 27.1$ & $147.6 \pm 33.1$ \\
\hline $\operatorname{HbA1C}(\%)$ & $7.1 \pm 1.31$ & $6.6 \pm 0.70$ \\
\hline Myocardial infarction (n; \%) & $23 ; 20.9$ & $2 ; 20$ \\
\hline Cerebrovascular ischemia $(\mathrm{n} ; \%)$ & $12 ; 10.9$ & $1 ; 10$ \\
\hline
\end{tabular}

At the beginning of the follow-up, plasma levels of liver enzymes, renal function and proteinuria were the samefor both groups; however, a significantly higher plasma ferritin level (mean \pm SD: $325.8 \pm 194.4 \mathrm{ng} / \mathrm{ml}$ ) in patients with OCI was demonstrated (patients with no OCI showed $139.1 \pm$ $136.8 \mathrm{ng} / \mathrm{ml} ; \mathrm{p}=.002$ ). The number of patients who reported risk factors for acquisition of $\mathrm{HCV}$ infection (blood transfusions, tattoos or piercings, or household contacts with a chronic HCV carrier) was similar in both groups. At the end of the follow-up (mean \pm SD:17.5 \pm 9 months), there was no difference in plasma levels of liver enzymes, diabetes control, cardiovascular events (myocardial infarction or cerebrovascular ischemia), renal function and proteinuria, as shown in Table 3.

le III: Kidney and liver parameters at the end of the follow-up.

\begin{tabular}{llll}
\hline & $\begin{array}{l}\text { Occult negative } \\
\text { HCV infection } \\
(\mathrm{n}=115)\end{array}$ & $\begin{array}{l}\text { Occult positive } \\
\text { HCV infection } \\
(\mathrm{n}=10)\end{array}$ & Significance \\
\hline Serum creatinine (mg/dl; mean \pm SD) & $2.1 \pm 1.1$ & $2.5 \pm 1.3$ & 0.282 \\
CrCl (m//min per 1.73 m²; mean \pm SD) $)$ & $42.4 \pm 23.4$ & $28.8 \pm 15$ & 0.076 \\
Proteinuria (gr/24 h; mean \pm SD) & $1.3 \pm 1.8$ & $0.5 \pm 0.5$ & 0.179 \\
Hematuria (n; \%) & $13 ; 11.8$ & $1 ; 1$ & 0.67 \\
ALT (IU/L; mean \pm SD) & $22.1 \pm 11.4$ & $16.6 \pm 4.5$ & 0.136 \\
GGT (IUL; mean \pm SD) & $50.9 \pm 39.9$ & $29.7 \pm 24.2$ & 0.271 \\
Ferritin (ng/ml; mean \pm SD) & $150.2 \pm 130.8$ & $163.2 \pm 81.4$ & $0.02 *$ \\
\hline
\end{tabular}

ALT: alanine aminotransferase

GGT: gamma-glutamyl transpeptidase

Although there were no significant differences in the liver and kidney parameters, the renal function decline rate tended to be more rapid in the group with OCI, as demonstrated by plasma creatinine and clearance values (Figure 1). Figure 1. Evolution of renal function in patients with occult negative/positive
HCV infection. (A) Initial and final plasma creatinine levels (mg/dl) (B) Initial and fina PROGRESSION OF RENAL DISEASE

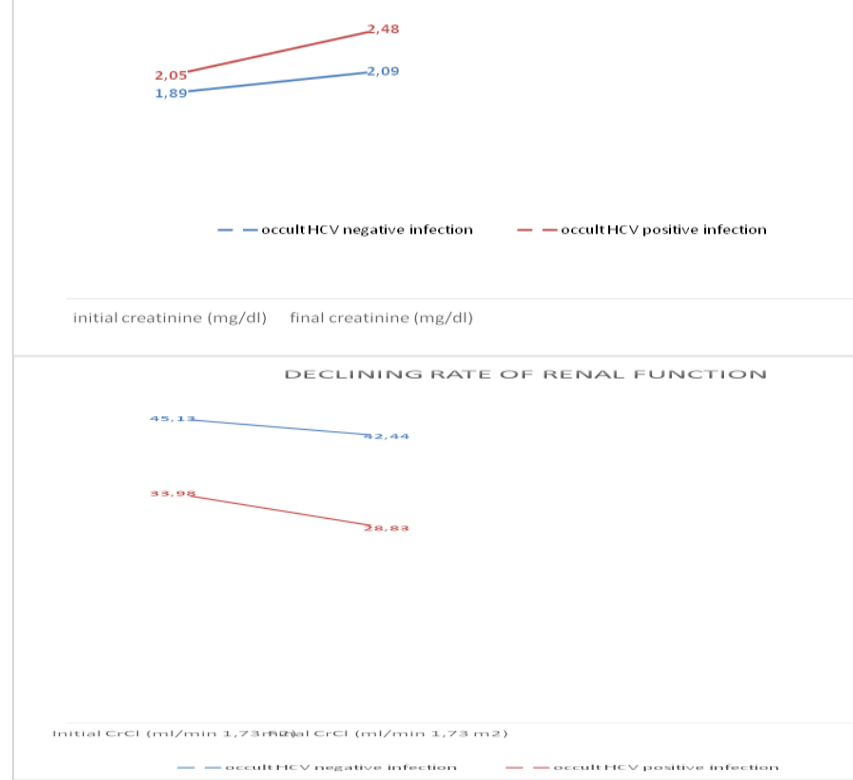

We did not identify an association between occult HCV infection and cardiovascular morbidity, but interestingly, we found that the patients with occult HCV infection had an incidence of $30 \%$ (3/10) monoclonal gammopathy vs. $0.87 \%$ $(1 / 115)$ of the patients without OCI $(\mathrm{p}=.003)$, over the follow-up.

\section{DISCUSSION}

OCI is a situation characterized by the absence of serological markers and the presence of HCV-RNA in the liver or in PBMCs. The presence of OCI has been documented in various populations, including patients with immune-mediated glomerulonephritis, cryptogenic hepatitis, NAFLD (non-alcoholic fatty liver disease) and lymphoproliferative disorders, as well as those undergoing hemodialysis, HIV-infected patients, drug users andthe healthy population [12].

Previous studies from our group had reported a high prevalence of OCI in groups of chronic kidney disease patients (hemodialysis 45\%, immune-mediated glomerulonephritis 39\%) $[14,15]$.The prevalence of anti-HCV in Spain is $1.7 \%(0.4 \%-2.6 \%)$ [16]. HCV infectiondetected by conventional serological markers is known to be highly prevalent in patients with DKD, reaching $19.5 \%[17,18]$. On these bases, this prospective study aimed to determine the prevalence of OCI and the possible clinical implications in a population of patients with DKD.

The prevalence of OCI found in patients with DKD in our study was $8 \%$, as demonstrated by the detection of HCV-RNA in PBMCs or in plasmaafter ultracentrifugation - higher than that found in the group with hereditary glomerulonephritis (3.8\%) [14]. In our study, risk factors for $\mathrm{HCV}$ infection were greater than those previously found in hereditary nephropathies (4\%), and less than those described in immune-mediated glomerulonephritis.

Chronic HCV infection is recognizably associated with liver steatosis [19]. Both HCV and metabolic syndrome are frequent disorders, and there is the possibility of overlapping. 
We did not find any difference in the liver parameters according to the presence of OCI.The only parameter we found with significant differences was serum ferritin, which could reflect liver inflammation.

The overweight patients were encouraged to reach ideal body weight because weight loss reduces liver steatosis and albuminuria and improves kidney function in patients with diabetes [20].For most patients, glycated hemoglobin (A1C) goals were $\leq 7.0 \%$ to avoid diabetic comorbidities. Although $\mathrm{BMI}$ and waist circumference tended to be higher in the $\mathrm{OCI}$ group, we did not find significant differences in the $\mathrm{HbA1C}$ insulin requirement for either group.

Whether $\mathrm{HCV}$ is an independent risk factor for cardiovascular disorders remains controversial [19]. The presence of $\mathrm{HCV}$ infection increased the risk of coronary artery disease in several studies [21-27].In addition, two community-based studies found that HCV infection was an independent predictor of cerebrovascular death, and also noted an association between serum HCV RNA levels and cerebrovascular mortality, hinting at a dose effect mechanism [28]. Other studies, however, have failed to identify an association between HCV infection and cardiovascular morbidity [29-30].We did not identify an association between OCI and cardiovascular morbidity, but we found that the patients with OCI had an incidence of $30 \%(3 / 10)$ monoclonal gammopathy vs. $0.87 \%(1 / 115)$ of the patients without OCI $(\mathrm{p}=.003)$. The incidence of HCV infection and other non-hepatic malignancies was examined in a Swedish cohort of patients infected with HCV. The study showed that the risk of B-cell non-Hodgkin's lymphoma and multiple myeloma were significantly increased [31]. OCI has also been described in patients with lymphoproliferative disorders, with a prevalence between $1.9 \%$ and 20\% [32-33]. Another study reported that the HCV-NS3 antigen is frequently expressed in the lymph nodes of anti-HCV- and serum HCV-RNA-negative patients with non-Hodgkin's lymphoma, suggesting the possibility of OCI in these patients[34].Although these findings remain to be confirmed, they suggest that HCV infection could be important in the pathogenesis of posttransplant lymphoproliferative disorder and other hematological malignancies. The lymphotropism of this virus could explain the relationship between infection by $\mathrm{HCV}$ and some lymphoproliferative disorders, particularly mixed cryoglobulinemia and B-cell non-Hodgkin's lymphoma [35]. In our cohort, it is difficult to establish a connection between, OCI, DKD and monoclonal gammopathy, particularly given the small number of patients with OCI; but the remarkable incidence (30\%) suggests new areas for research.The primary clinical manifestations of DKD are albuminuria, occasionally microscopic hematuria, and in manypatientsprogressive kidney disease [36-38]. We did not find a higher prevalence of hematuria in the OCI group.At the end of the follow-up period, the progression of kidney disease tended to be more rapid in the group with occult HCV infection; however, the difference was not statistically significant. Proteinuria was similar in both groups, as was the use of RAAS therapy. Our group has also described the tendency for patients with immune-mediated glomerulonephritis and OCI to progress to end stage renal disease more rapidly than patients OCI negative ones. [14].One of the limitations of our study is the size of the series. However, the trends that are complementary with previous findings justify a preliminary recognition of these associations, specifically those related to the more rapid progression of kidney disease in patients with OCI.

\section{CONCLUSIONS}

In conclusion, for patients with chronic renal failure secondary to DKD, there is a lower prevalence $(8 \%)$ of OCI compared with the prevalence in patients with immune-mediated glomerular nephropathies (39\%), but OCI is higher than in the general population and in hereditary nephropathies [14]. These data indicate that the presence of OCI plays a limited role in the control of diabetes, cardiovascular risk or liver steatosis in these patients. In the group with OCI, however, the progression of renal disease tended to be more rapid than in the non-OCI group and showed a remarkable and unexpected prevalence of monoclonal gammopathy.

\section{ACKNOWLEGDMENTS}

This work was funded by grants PI 11/00585 and PI 12/00204 from the Fondo Investigación Sanitaria, Instituto de Salud Carlos III (ISCIII), Spain. Our group is also supported by FEDER Funds from the European Union as part of REDinREN (RETICS, ISCIIII).

\section{REFERENCES}

[1] Simo R, Hernandez C, Genesca J, Jardi R, Mesa J. High prevalence of hepatitis C virus infection in diabetic patients. Diabetes Care 1996; 19: 998-1000.

[2] Jadoon NA, Shahzad, MA, Yaqood R. et al.Seroprevalence of hepatitis $\mathrm{C}$ in type 2 diabetes: evidence for a positive association. Virol J 2010; 7: 304-309.

[3] Cusi K. The relationship between hepatitis $\mathrm{C}$ virus infection and diabetes: time for a divorce? Hepatology 2014; 60:1121-3.

[4] White DL, Ratzin V, El-Serag HB. Hepatitis C infection and risk of diabetes: a systematic review and meta-analysis. J Hepatol 2008; 49:831-44

[5] Naing C, Mak JW, Ahmed SI, Maung M. Relationship between hepatitis $C$ virus infection and type 2 diabetes mellitus: meta-analysis. World J Gastroenterol 2012; 18: 1642-51

[6] Eslam M, Khattab MA, Harrison SA. Insulin resistance and hepatitis C: an evolving story. Gut 2011; 60: 11391151.

[7] Kawaguchi Y, Mizuta T. Interaction between hepatitis C virus and metabolic factors. World J Gastroenterol 2014; 20: 2088-2901.

[8] Kawaguchi T, Yoshida T, Harada M, Hisamoto T,Nagao Y Ide T, et al. Hepatitis $\mathrm{C}$ virus down-regulates insulin receptor substrates 1 and 2 through up-regulation of supresor of cytokine signaling 3. Am J Pathol 2004; 165: 1499-1508.

[9] Persico M, Russo R, Persico E, Svelto M, Spano DAndolfo I, et al. SOCS3and IRS -1 gene expression differes between genotype 1 and genotype 2 hepatitis $\mathrm{C}$ virus infected HepG2 cells. Clin Chem Lab Med 2009; 47: 1217-25

[10] Pazienza V, Vinciguerra M, Andriulli A, Mangia A.Hepatitis C virus core protein genotype $3^{\mathrm{a}}$ increases SOCS7 expression through PPAR-c in Huh-7 cells. J Gen Virol 2010;91: 1678-1686.

[11] Ruhl CE, Menke A, Cowie CC, Everhart JE.Relationship of hepatitis C virus infection with diabetes in the U.S. population. Hepatology 2014; 60: 1139-49.

[12] Carreño V. Seronegative occult hepatitis C virus infection: clinical implications. J Clin Virol 2014; 61:315-320.

[13] Bartolome J, Lopez-Alcorocho, Castillo I, Rodriguez-Iñigo E, Quiroga JA, Palacios R, et al Ultracentrifugation of serum samples allows detectionof hepatitis $C$ virus RNA in patients with occult hepatitis C virus. J Virol 2007; 81: 7710-5.doi:10.1128/JVI.02750-06. 
[14] Castillo I , Martinez-Ara J , Olea T, Bartolome J , Madero R, Hernandez E, et al. High prevalence of occult hepatitis $\mathrm{C}$ virus infection in patients with primary and secondary glomerular nephropathies.Kidney Int 2014; 86: 619-24.

[15] Barril G, Castillo I, Arenas MD, Espinosa M, Garcia-Valdecasas J, Garcia-Fernández $\mathrm{N}$, et al. Occult hepatitis $\mathrm{C}$ virus infection among hemodialysis patients.J Am Soc Nephrol. 2008; 19:2288-2292.

[16] Gower E , Estes C , Blach S, Razavi-Shearer K, Razavi H. Global epidemiology and genotype distribution of the hepatitis $\mathrm{C}$ virus infection. J Hepatol 2014; 61:S45-S57.

[17] Crook ED, Penumalee S, Gavini B, Filippova K. Hepatitis C is a predictor of poorer renal survival in diabetic patients. Diabetes Care 2005; 28: 2187-91.

[18] Soma J, Saito T , Taguma Y, Chiba S, Sato H, Sugimura K, et al. High Prevalence and Adverse Effect of Hepatitis C Virus Infection in Type II Diabetic- Related Nephropathy. J Am Nephrol Soc 2000; 11: 690699.

[19] Negro F. Facts and fictions of HCV and comorbidities: steatosis, diabetes mellitus, and cardiovascular diseases. J Hepatol 2014; 61: S69-S78.

[20] E. Morales, Valero MA, Leon M, et al. Beneficial effects of weight loss in overweight patients with chronic proteinuric nephropathies. Am J Kidney Dis 2003; 41; 319.

[21] Vassalle C, Masini S, Bianchi F, Zucchelli GC. Evidence for association between hepatitis $\mathrm{C}$ virus seropositivity and coronary artery disease. Heart 2004; 90:565-566.

[22] Alyan O, Kacmaz F, Ozdemir O, Deveci B, Astan R, Celebi AS, et al. Hepatitis $\mathrm{C}$ infection is associated with increased coronary artery atherosclerosis defined by modified Reardon severity score system. Circ J 2008;72:1960-1965.

[23] Marelli D, Bresson J, Laks H, Kubak B, Fonarow G, Tsai FC, et al. Hepatitis $\mathrm{C}$ positive donors in heart transplantation. Am J Transplant 2002; 2:443-447.

[24] Haji SA, Starling RC, Avery RK, Mawhorter S, Tuzcu EM, Schoenhagen P,et al. Donor hepatitis-Cseropositivity is an independent risk factor for the development of accelerated coronary vasculopathy and predicts out come after cardiac transplantation. J Heart Lung Transplant 2004;23:277-283.

[25] Younossi ZM, Braun WE, Protiva DA, Gifford Jr RW, Straffon RA. Chronic viral hepatitis in renal transplant recipients with allografts functioning for more than 20 years. Transplantation 1999;67:272-275.

[26] Butt AA, Xiaoqiang W, Budoff M, Leaf D, Kuller LH, Justice AC. Hepatitis $\mathrm{C}$ virus infection and the risk of coronary disease. Clin Infect Dis 2009;49:225-232.

[27] Younossi ZM, Stepanova M, Nader F, Younossi Z, Elsheikh E. Associations of chronic hepatitis $\mathrm{C}$ with metabolic and cardiac outcomes. Aliment PharmacoL Ther 2013;37:647-652.

[28] Lee MH, Yang HI, Wang CH, Jen CL, Yeh SH, Liu CJ, et al. Hepatitis $\mathrm{C}$ virusinfection and increased risk of cerebrovascular disease. Stroke2010;41:2894-2900.

[29] Völzke H, Schwahn C, Wolff B, Mentel R, Robinson DM, Kleine V, et al. Hepatitis $\mathrm{B}$ and $\mathrm{C}$ virus infection and the risk of atherosclerosis in a general population. Atherosclerosis 2004;174:99-103.

[30] Arcari CM, Nelson KE, Netski DM, Nieto FJ, Gaydos CA. No association between hepatitis $\mathrm{C}$ virus seropositivity and acute myocardial infarction. Clin Infect Dis 2006; 43: e53-e56.

[31] Kristiansen MG, Løchen ML, Gutteberg TJ, Mortensen L, Eriksen BO, Florholmen J. Total and cause-specific mortality rates in a prospective study of community-acquired hepatitis $\mathrm{C}$ virus infection in northern Norway. J Viral Hepat 2011; 18: 237-244.

[32] Youssef SS, Nasr AS, El Zanaty T, El Rawi RS, Mattar MM. Prevalence of occult hepatitis $\mathrm{C}$ virus in Egyptian patients with chronic lymphoproliferative disorders. Hepat Res Treat 2012; 2012; 429784.doi: 10.1155/2012/429784.

[33] Maryam Farahani, Farah Bokharaei- Salim, Masood Ghane, Alii Basi, Parisa Meysami and Hossein Keyvani. Prevalence of Occult Hepatitis C Virus Infection in Iranian PatientsWith Lymphoproliferative Disorders. J Med Virol 2013; 85 (2):235-40.

[34] Ghada Mohamed El-sayed, Waleed Seif El-din Mohamed, Mohamed Akram Nouh, Manar Mohamed Moneer and Hadir Ahmed El-Mahallawy. Viral Genomes and Antigen Detection of Hepatitis B and C Viruses in involved Lymph Nodes of Egyptian Non-Hodgkin's Lymphoma Patients. Egypt J Immunol 2006;13 (1):105-14.

[35] Pena LR,Nand S, De Maria N, Van Thiel DH. Hepatitis C virus infection and lymphoproliferative disorders. Dig Dis Sci 2000; 45 1854-1860.
[36] Matsumura N, Hanatani M, Nishino T. The clínico-pathological significance of hematuria in diabetics. Nihon Jinzo Gakkai Shi 1994; 36: 1036.

[37] O'Neill WM , Wallin JD, Walker PD. Hematuria and red cell casts in typical diabetic nephropathy. Am J Med 1983; 74: 389.

[38] Lopes de Faria JB , Moura LA , Lopes de Faria SR.Glomerular hematuria in diabetics. Clin Nephrol 1988; 30: 117 . 